\title{
Application of a roof support monitoring system for analysis of work parameters of a powered longwall system
}

\author{
Dawid Szurgacz ${ }^{1, *}$, and Jarosław Brodny ${ }^{2}$ \\ ${ }^{1}$ Center of Hydraulics DOH Ltd, ul. Konstytucji 147, 41-906 Bytom, Poland \\ ${ }^{2}$ Silesian University of Technology, Faculty of Organization and Management, Roosevelta 26, 41-800 \\ Zabrze, Poland
}

\begin{abstract}
In recent years, the world economy has undergone dynamic technological changes known as the Fourth Industrial Revolution. One of the main areas of these changes is the practical use of information systems to optimize production processes. Universal digitization results in the emergence of cyber-physical systems that, apart from the Internet of Things, are beginning to be used more and more widely in many industries. These changes are being applied also in the mining industry, including the Polish coal mining. Competition on the global energy market and growing requirements in the field of work safety and environmental protection make it necessary to take decisive action to modernize and adapt this industry to global standards. The article presents the results of the use of information technology in the process of hard coal production in mines owned by Polska Grupa Górnicza S.A., a leading coal mining company in Poland. The paper focuses on the operation of the powered roof systems which, in addition to protecting the work environment (longwall area), is also a construction base for the entire longwall system. The monitoring of the operation of individual sections of the support therefore allows control and evaluation of the condition and efficiency of the entire powered unit. The solution proposed by the authors should enable this process to be carried out.
\end{abstract}

\section{Introduction}

A longwall system with roof caving is the dominant system of operation in the world coal mining industry. The use of this system enables high-performance operation. In order for this process to be effective and run smoothly, a number of requirements must be met. The main factors affecting the efficiency of this system are the mining and geological conditions of a given field of exploitation as well as technical equipment of the longwall [1]. In terms of mining and geological conditions, the basic significance in addition to the location and size of the deposit are natural hazards occurring in the area of exploitation. These threats slow down the operation, increase its costs and pose a danger to employees. Methane and fire hazards are the most unfavourable $[2,9,10,11]$. It should also be noted that the occurrence

\footnotetext{
* Corresponding author: dawidszurgacz@doh.com.pl
} 
of hazards in the mining exploitation process is inextricably linked with this process, and results from disturbance of balance in rock mass. The effects of these threats in terms of underground mining can be minimized but not entirely removed. Methods aimed at reducing such hazards are more and more effective.

Another very important element that has an impact on the efficiency of the mining operation process is the technical systems used, mainly the machines. This applies to all machines that, due to difficult and not entirely predictable working conditions, must have very high technical parameters. This applies to machines used directly for rock mass excavation, horizontal transport conveyors and vertical transport machines. Roof support particularly important in the underground mining process. Its main task is to protect mine workings in which the entire mining production process is carried out. There are two types of a roof support. These are gallery and roof supports. The type depend on the working in which it is used. The gallery support uses friction joints, thanks to which it can passively cooperate with the rock mass [1].

The roof support is an essential element of the mining process $[4,5,6]$. It secures the working area and works with machines of the longwall system, namely a shearer or a plow and a face conveyor $[3,7,8]$. The support comprises powered sections, they are presented in Figure 1 together with mounted face conveyor.

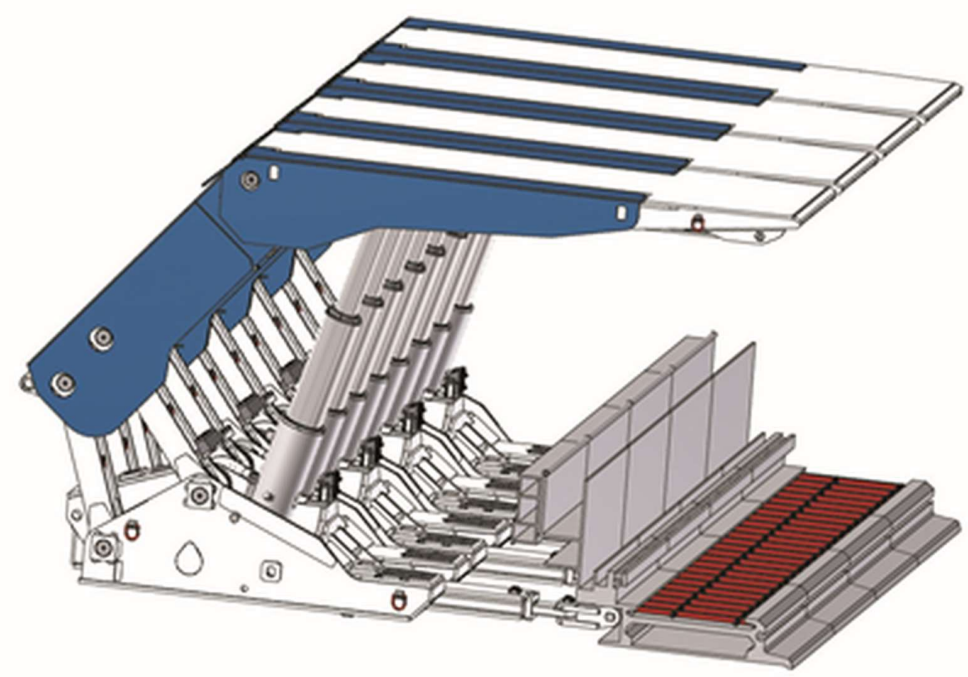

Fig. 1. A powered roof support section.

It is extremely important to select adequate hydraulic and control systems that will be used with this type of the support. The control systems have a very large impact on the speed and efficiency of the support. At the same time, they decide on the effectiveness of the entire longwall system. Therefore, the selection of an appropriate control system for the powered roof support is of key importance for the operation of the entire powered complex.

Previous cases show that even in favourable operating conditions (no natural hazards, low depth, no operational residue) and with the use of modern machinery and equipment (shearer, conveyor), a poorly coordinated control system can make the complex work more difficult.

The control system has a significant impact on the maintenance of the roof and deformation of the rock mass. This impact may include both settlement of the roof and uplifting of the floor, which further complicates the working conditions of the support.

The powered roof support impacts on the entire underground mining process, therefore, the authors decided to conduct research aimed at determining the actual impact of the 
powered roof support on operational parameters. It is essential to design or select proper control system and ensure the accessibility to the operating parameters of the individual sections of the support.

Knowledge of these parameters, related to the results of the operation process gives the opportunity to reliably evaluate the applied system.

The authors carried out work whose task was to determine the parameters of the prototype work of the powered roof support equipped with an innovative system of registration and visualization of its work parameters. This system aims to record, archive and visualize the most important parameters of the section. In combination with the recorded parameters of the work of the other machines of the complex, it should source of information that will provide wade range of data on the work of the entire complex. Obtained results should also be used to select the appropriate roof support for given operating conditions.

However, a clear and up-to-date visualization of the work parameters of the section gives the possibility of direct modification of these parameters to ensure optimal operation.

Taking into account the increasing requirements regarding the parameters defining the visualization of the section and longwall geometry, research was carried out for the prototype section of the powered roof support. The scope of the research, part of which was presented in the article, included:

- inclinometer sensors for the prototype section under surface conditions that measured the position of individual elements of the section,

- mounted pressure sensor that measured pressure change in section's legs,

- defining section and longwall geometry that allowed to collect data for the visualization test.

Registration of so many parameters of the section work requires the use of appropriate IT tools. Their processing and archiving also must involve dedicated IT tools. It is also an opportunity to apply the innovations and solutions of the Fourth Industrial Revolution to the mining industry which will increase digital capabilities of the underground exploitation. The article briefly presents and discusses the basic functions of the system for registration and visualization of operating parameters of a powered roof support

\section{Related works}

Visualization of the support and the entire data set registered during operation is one of the main goals of the developed system. The effectiveness of the work of the proposed innovative electrohydraulic system for controlling the powered longwall system is to a large extent dependent on how the data is presented. It should be remembered that in the underground conditions clear and transparent access to data may determine the quality and efficiency of the system's operation. The recorded data should be made available in a transparent and simple way. There should be different access data levels. The low level users will be able to access to only limited set of information whereas the highest users can access the most sensitive data on the system. Therefore, the archiving, analysis and visualization system works in several areas. In this respect, it is particularly important to provide information to the operators of the complex. It is also very important to properly train the staff and present the developed system. Proper preparation of the interface was discussed in detail, so that in a transparent and friendly manner it would convey the information of the recipient, also taking into account its intellectual level.

It was assumed that good visualization, in the aesthetic and ergonomic sense, can have a very positive effect on the effectiveness of information transfer. In this respect, it is also important to develop a range of data that is necessary and required for individual groups of recipients. Currently used data logging systems and their processing allow transmission of a large amount of information, which in many cases is not necessary. 
The discussed visualization system presents basic data for operators. These include the location of the longwall face, the value of the current pressure in the space under the piston of the legs in individual sections, information on the movement and location of the shearer in the longwall and error lines of sensors, valves and cable connections. The versatility of the developed solution allows also to adjust the interface to the individual preferences of the user.

\section{Porposed work}

Appropriate software was developed based on data sent by drivers, pressure sensors and sensors determining the position of the powered roof support. The software was designed to visualize the work of the longwall complex. The program is used to visualize the operation of the longwall system, and in particular the parameters of the roof support. An example of the visualization method of the complex is shown in Figure 2.

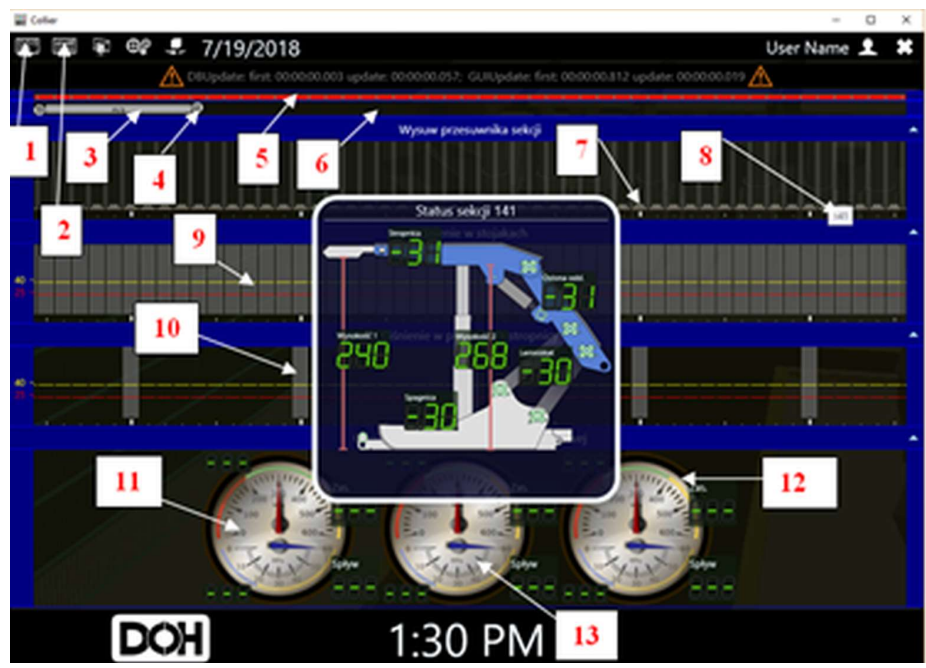

Fig. 2. Display of results of monitoring the work parameters of the powered roof support section.

The presented system enables monitoring of many parameters of the operation process and making adjustments in this process. Figure 2 indicates the most important elements of the developed system.

Number 1 indicates the program menu allowing selection of the following options:

- recording set parameters of the longwall system (file);

- recording the work history of the complex (file);

- setting and saving work parameters of the coal-plow complex and changing the position of

- the target line, approaching coal and conveyor (control);

- setting the conveyor operation parameters and viewing the parameters of the complex;

- preparation of shift, daily and monthly reports (view);

- support (software version, device manufacturer);

- language (German, English or Polish).

Number 2 is a graphic menu allowing to:

- save the set parameters,

- block horizontal and vertical stretching of the system and the longwall;

- move the view of the longwall complex and the longwall with the cursor (arrow); 
- enlarge the view of the longwall complex and the longwall (magnifier);

- set mining parameters;

- set the roof support and coal bead operation parameters.

The remining numbers represent as follows:

3 - position of the shearer;

4 - the direction of the shearer;

5 - operation of the longwall conveyor;

6 - longwall length;

7 - extension of the section's conveyor;

8 -section status defining the geometric parameters of the position of the section in the longwall;

9 - pressure value in the legs;

10 - pressure value in the canopy's cylinder actuator;

$11,12,13$ - visualization of pressure value in subassemblies of the roof support section.

\section{Discussion}

The visualization program presents the current condition of the longwall with all monitored parameters of the machines in the complex. The user can adjust the display and select the parameters that will be presented on the screen. Having the appropriate authorization, he may review and control these data at any time. In the case of powered roof support sections, the activities related to its progress are carried out between ten and twenty times a day. Such operations last no longer than a minute, and the remaining time the section is not being operated. Some measurement values remain unchanged during this time, others change slowly, which determines the developed database schema.

In practice, it happens that data from the system may come irregularly or incompletely due to power off in the longwall, controller or power supply failure, mechanical interruption of the communication interface, etc. The designed database enables their registration and analysis despite incomplete data.

Data from the database are also used (in addition to visualization), to create reports on operation, diagnostics of some section elements, two- and three-dimensional diagrams, etc. Therefore, it will be possible to view data according to various types of criteria (filters), for a given measurement in one section, for all measurements of a single section, or for the entire longwall in the required period of time, etc. Due to the need (in some cases) to analyse the data over a longer period of time, the data will be stored (archived) from operation of the entire length of the longwall. In the longer term, this will allow to compare different systems, machines and types of supports.

Data from each section of the electrohydraulic control system will be sent to the longwall computer with a data line. It is proposed to transfer data from a longwall computer with a fiber optic link, possibly via an Ethernet cable. It assumes data transmission (data refreshing) from the longwall system computer to the main database (central computer) every second. With large systems or difficult conditions, the data refresh time can be extended to the time necessary for proper data transmission along the communication line.

The developed data registration and visualization system during testing on the test bench is shown in Figure 3. There is also an overview of the distribution of sensors in the section. In contrast, Figure 4 shows the view of the interface itself during the examination of this section. 


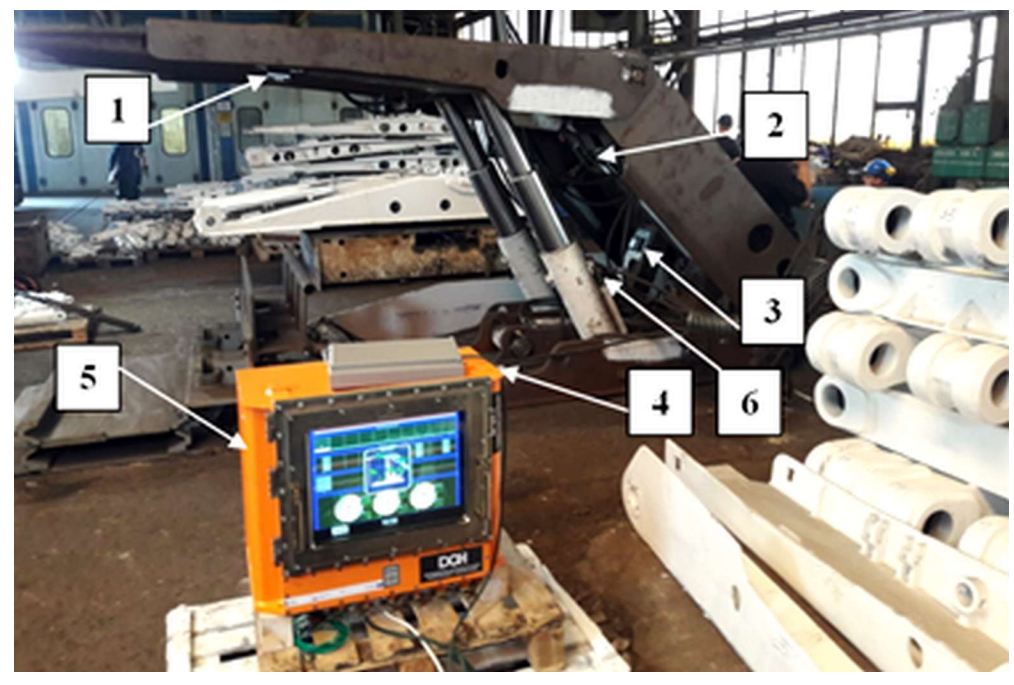

Fig. 3. The arrangement of sensors in the powered roof support section for the visualization of its operation parameters: 1 - canopy location sensor, 2 - shield support location sensor, 3 - lemniscate cable location sensor, 4 - floor base location sensor, 5 - a PC, 6 - pressure sensor.

The basic image on the screen (Figure 4) shows the location of the longwall front, the value of the current pressure in the space under the piston of the legs in individual sections, and the geometry of the section. It also provides information about the error line of sensors, valves and cable connections. The presented example shows a longwall view and a diagnosis of the state of the devices controlling the powered roof support. For instance, If an electromagnetic valve failure occurs, an error message of a given slider valve in section $\mathrm{X}$ appears. Similarly, each time the lockout switch is pressed, the bar shows the area to disable automatic functions. Pressure and distance sensors as well as the condition of cable connections are also diagnosed.

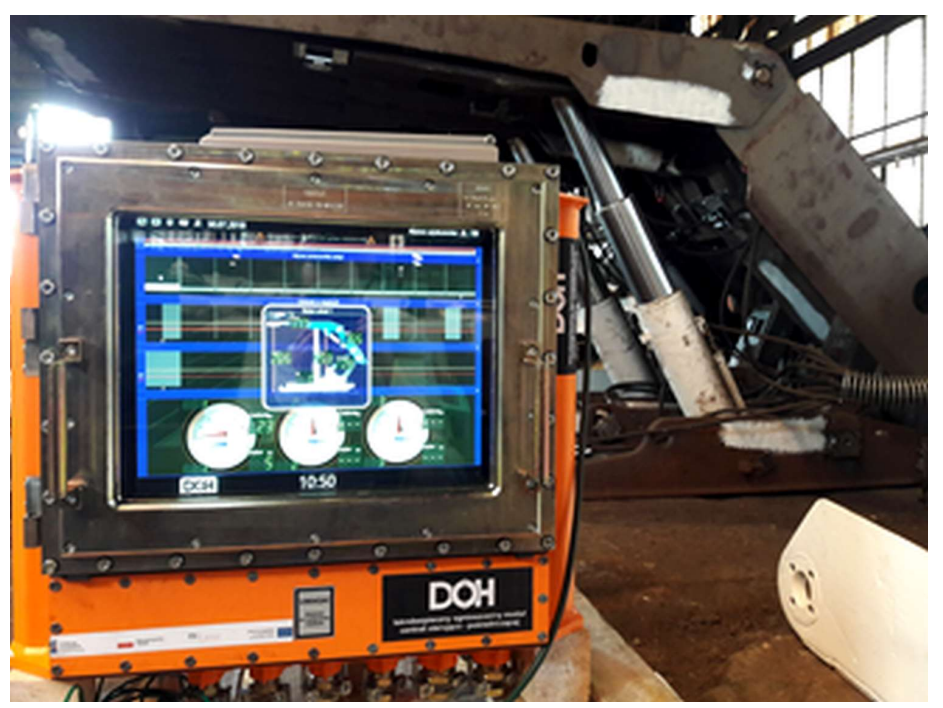

Fig. 4. Interface for monitoring the operation parameters of the longwall system during bench tests of the support section. 


\section{Conclusion}

The system for visualization of the longwall unit, developed and briefly described, creates a wide range of applications in practice. It will enable control and assessment of the condition and efficiency of the entire powered complex. The developed system is currently in the underground testing phase. Very good results were obtained during bench tests. It should also be emphasized that the system is based on own solutions resulting from many years of experience of the authors. It should be noted that the specificity of working conditions in underground mining excavations causes that systems used in surface conditions have not worked well during mining operations. While developing this system, however, many solutions from other industries were used to construct control systems. Therefore, the study is universal and enables integration with other information systems in the mine. Ultimately, it is planned to monitor all machines involved in the mining production process and fully synchronize this system. The presented solution arouses great interest of mining enterprises. It is an example of the practical application of the idea of Industry 4.0. More and more often, also in the relatively conservative industry, which is mining, the need to introduce modern solutions is noticed. For the mining industry, the introduction of a new control system should, however, be crucial, because it is associated with the improvement of safety and efficiency of the entire operation process.

The work was carried out within the project "Innovative electrohydraulic control system for powered roof support. POIR.01.01.01-00-1129/15". Intelligent Development Operational Programme 2014-2020 carried out by the National Centre for Research and Development.

\section{References}

1. J. Brodny, Archives of Mining Sciences, 57:1, 209-227 (2012)

2. J. Brodny, M. Tutak, 16th International Multidisciplinary Scientific GeoConference SGEM 2018 Conference proceedings, 2:1 (2016) DOI: 10.5593/SGEM2016/B12/S03.085

3. K. Stoiński, M. Mika, J. Min. Sc., 39:1, 72-77 (2003)

4. K. Stoiński, Obudowy górnicze $w$ warunkach zagrożenia wstrzasami górotworu (Główny Instytut Górnictwa, Katowice, 2000)

5. K.S toiński, Zmechanizowane obudowy ścianowe do warunków zagrożenia wstrzasami górotworu (Główny Instytut Górnictwa, Katowice, 2018)

6. K. Stoiński, D. Szurgacz, Przegląd Górniczy, 7, 8-17 (2017)

7. D. Szurgacz, J. Brodny, 18th International multidisciplinary scientific GeoConference SGEM 2018 Conference proceedings, 18:1.3, 343-350 (2018) DOI: doi.org/10.5593/sgem2018/1.3

8. D. Szurgacz, J. Brodny, E3S Web Conferences, 29, 00006 (2018)

9. D. Szurgacz, L. Sobik, J. Brodny, Geolinks International Conference on Geosciences. Conference proceedings, 1:1 (2019)

10. M. Tutak, J. Brodny, IOP Conf. Ser.: Earth Env. Sc., 95, 042025 (2017) DOI: doi:10.1088/1755-1315/95/4/042025

11. M. Tutak, J. Brodny, Energy and Clean Technologies SGEM2016 Conference Proceedings, VIII:3, 75-82 (2016) DOI: 10.5593/SGEM2016/HB43/S06.011 